\title{
INVESTIGAÇÃO ACERCA DA PEDAGOGIA DO CONCEITO E SUA APLICABILIDADE NO ENSINO DE FILOSOFIA NO ENSINO MÉDIO
}

\section{INVESTIGATION ABOUT PEDAGOGY OF CONCEPT AND ITS APPLICABILITY IN TEACHING PHILOSOPHY IN MIDDLE SCHOOL}

\author{
William Gustavo da Silva Macedo \\ Flávio José de Carvalho ${ }^{2}$
}

Recebido em: 05/2018

Aprovado em: 05/2018

\begin{abstract}
Resumo: O presente artigo tem por objetivo investigar a Pedagogia do Conceito e sua possível aplicabilidade nas salas de aulas do Ensino Médio, veiculada pelas abordagens dos filósofos Gilles Deleuze e Félix Guattari e com o intuito de compreender os possíveis efeitos, contribuições e impactos no Ensino de Filosofia. Como base teórica para tal utilizamos das contribuições teóricas de filósofos franceses Gilles Deleuze e Félix Guattari, norteados pela obra $O$ que é a Filosofia? (1992), entre outros pesquisadores que venham a contribuir com a investigação acerca das contribuições do Ensino de Filosofia. Nesse sentido, percebe-se a necessidade de buscar estratégias que estimulem o filosofar nas aulas de Ensino Médio, que proporcionem momentos investigativos, problematizadores, que possibilitem pensar a criação de conceitos. Sobre este último aspecto, denotamos a característica marcante da Filosofia na apreensão filosófica de Deleuze e Guattari. Por fim, pretendemos analisar a proposta filosófica sobre a Pedagogia do Conceito no Ensino de Filosofia, bem como destacar uma proposta de Ensino de Filosofia orientada pela Pedagogia do Conceito
\end{abstract}

Palavras-chave: Pedagogia do Conceito. Ensino de Filosofia. Deleuze.

\begin{abstract}
This article aims to investigate the Pedagogy of the Concept and its possible applicability in the high school classrooms, conveyed by the approaches of the philosophers Gilles Deleuze and Félix Guattari and with the intention of understanding the possible effects, contributions and impacts in the Teaching of Philosophy. As a theoretical basis for such research we use the theoretical contributions of French philosophers Gilles Deleuze and Félix Guattari guided by the work What is Philosophy? (1992), among other researchers who contribute to the investigation about the contributions of philosophy teaching. In this sense, we perceive the need to seek strategies that encourage the philosophizing in the classes of High School, that provide investigative, problematizing moments, that make possible to think the creation of concepts. On this last aspect, we denote the striking feature for Philosophy in the philosophical apprehension of Deleuze and Guattari. Finally, we intend to analyze the philosophical proposal on the Pedagogy of the Concept in the Teaching of Philosophy, as well as to highlight a proposal of teaching of philosophy guided by the Pedagogy of Concept.
\end{abstract}

Keywords: Pedagogy of Concept. Teaching Philosophy. Deleuze.

\footnotetext{
${ }^{1}$ Graduado em Filosofia (UFCG), mestrando em Filosofia (UFCG), professor de Filosofia da rede pública de ensino do estado do Rio Grande do Norte. Email: umgustavomacedo@gmail.com

${ }^{2}$ Doutor em Filosofia. Professor do Mestrado PROF-FILO, núcleo UFCG. email: flavio.carvalho@ufcg.edu.br
} 


\section{Introdução}

O presente trabalho tem por intuito investigar as contribuições da Pedagogia do Conceito para o Ensino de Filosofia no Ensino Médio. Para tal, trazemos como embasamento filosófico os filósofos franceses Gilles Deleuze (1925-1995) e Félix Guattari (1930-1992) e sua noção de Pedagogia do Conceito presente na obra O que é a Filosofia? (1992). Assim, o debate sobre processos diferenciados e inovações no âmbito educacional, fomentam uma tentativa de compreender o impacto do desenvolvimento da aplicação desta pesquisa no espaço escolar, e como esta pode possibilitar aos estudantes do Ensino Médio na disciplina de Filosofia o contato com um itinerário filosófico norteado pela Filosofia deleuzo-guattariana, percebida como Filosofia criadora de conceitos, a qual incita a indagação, apropriação e criação de conceitos que são próprios do exercício filosófico.

Nessa perspectiva, o objeto de investigação desta pesquisa concentra-se primordialmente no Ensino de Filosofia sob o viés da Pedagogia do Conceito e dos principais elementos desta, como: o Conceito compreendido como multiplicidade, haja visto que cada conceito possui uma singularidade, sendo composto de diversos componentes que se definem por entre eles, e sempre remetendo-se a um problema; o Plano de Imanência, enquanto uma espécie de plano que os filósofos franceses definem como único suporte para os conceitos, isto é, um plano que envolve os conceitos respeitando suas respectivas singularidades; o Personagem Conceitual, que não pode ser entendido como o filósofo ou representante dele, mas como heterônimos do filósofo, para assim pensar uma educação filosófica que incite a atitude filosófica, que problematize como se dá o movimento de criação conceitual desenvolvida pelos filósofos, como designo a contribuir no Ensino de Filosofia na sala de aula do Ensino Médio.

Tal artigo possui como objetivo geral a compreensão sobre os possíveis efeitos, contribuições e impactos no Ensino de Filosofia, pretendendo criar condições que permitam pensar a criação de conceitos, os quais escapem do ensino historiográfico e contribuam para uma formação filosófica dos estudantes e professores de Filosofia; bem como objetivos específicos de identificar o papel de Ensino de Filosofia no espaço escolar, analisar o perfil dos estudantes e da comunidade escolar no que compete ao ensino filosófico, e por fim, estabelecer estratégias de investigação acerca de como se dá o processo de criação de conceitos segundo o viés deleuzo-guattariano.

No que compete abordar a Pedagogia do Conceito, apresentamos como pressuposto o pensamento dos dois filósofos contemporâneos supramencionados. Desse modo, temos que as 
compreensões deleuzo-guattarianas acerca do objeto investigado são apreendidas pela capacidade de formar, criar e recriar conceitos, que surgem como um processo investigativo, sendo o filósofo aquele que media esse processo, aquele que precisa se perguntar, que precisa de problemas, os quais o forcem a pensar. Portanto, compreendemos que estas apreensões acerca de uma Filosofia criadora de conceitos parecem dialogar com a apresentação da figura de um professor-filósofo, o qual possa possibilitar o pensar filosófico, o questionar o mundo e seu cotidiano; desse modo, utilizando da História da Filosofia como caminho e não como a própria Filosofia.

Nossa motivação parte da vivência com a Pedagogia do Conceito, a qual ocorre de forma continuada no espaço do cotidiano escolar, sendo decorrente também da vivência durante a época de graduação. Tal pesquisa se pauta num modelo de ensino que visa a atitude filosófica, o questionar-se, e que busca refletir sobre o movimento de criação de conceitos, este último enquanto elemento específico da filosofia. Desse modo, por meio da Pedagogia do Conceito buscamos pensar a construção de um itinerário filosófico que torne o espaço escolar também um ambiente de construção, criação e investigação filosófica, e não apenas um espaço de transmissão de saberes e informações de Filosofia e sua história.

Por fim, estabelecemos discussões acerca das principais contribuições da Pedagogia do Conceito para o Ensino de Filosofia no Ensino Médio e sobre a aplicabilidade da temática pesquisada no processo educacional; que auxilia na formação dos estudantes no que se refere ao desenvolvimento da capacidade de pensar a Filosofia enquanto criação de conceitos, com intuito de desenvolver uma educação filosófica que viabilize a própria atitude filosófica, em vista da necessidade de repensar contribuições para o processo formativo dos estudantes do Ensino Médio.

\section{A pedagogia do conceito e o ensino filosófico}

Tendo como pressuposto a investigação da Pedagogia do Conceito, reconhecemos a Filosofia de Gilles Deleuze e Félix Guattari como uma possibilidade diferenciada de pensar o Ensino de Filosofia, que pode contribuir diretamente aos estudantes do Ensino Médio nas aulas de Filosofia. Com vistas na atuação do professor de Filosofia, provido desta compreensão acerca do que vem ser a Filosofia para os filósofos franceses, apontamos como proposta para a disciplina um modelo que não vislumbra somente os moldes tradicionais, àqueles que visam primordialmente o conteúdo, mas uma Filosofia que almeje a própria atividade filosófica, esta 
compreendida como criadora de conceitos.

Assim, buscamos oportunizar esse processo por meio do professor de Filosofia no exercício de sua docência, na tentativa de constituir um processo investigativo filosófico que evidencie o aprender enquanto experiência filosófica. Desse modo, concordamos que:

O filósofo é o amigo do conceito, ele é o conceito em potência. Quer dizer que a Filosofia não é uma simples arte de formar, de inventar ou de fabricar conceitos, pois os conceitos não são necessariamente formas, achados ou produtos. A Filosofia, mais rigorosamente, é a disciplina que consiste em criar conceitos. O amigo seria o amigo de suas próprias criações? [...] criar conceitos sempre novos é o objeto da Filosofia. É porque o conceito deve ser criado que ele remete ao filósofo como àquele que o tem em potência, ou que tem sua potência e sua competência (DELEUZE; GUATTARI, 1992, p. 11).

No que diz respeito a Pedagogia do Conceito, compreendemos no fragmento acima a relação do conceito com o filósofo. Desse modo, vemos que esta proposta pedagógica possibilita o desenvolvimento de investigação acerca do exercício filosófico de criação de conceitos, sendo este movimento próprio da Filosofia deleuzo-guattariana.

Dessa maneira, a Filosofia deleuzo-guattariana incita um movimento investigativo, problematizador, que possibilita investigar o processo de criação de conceitos, sobre o qual denotamos ao conceito à característica marcante para a Filosofia nessa apreensão filosófica, pois é o conceito que distingue a Filosofia de outros campos dos saberes, como a ciência, sobre a qual Deleuze e Guattari afirmam que "é inútil atribuir conceitos [...] mesmo quando ela se ocupa dos mesmos "objetos", não é sob o aspecto do conceito, não é criando conceitos" (DELEUZE; GUATTARI, 1992, p. 46), isto é, por mais que a ciência aborde conceitos, não é uma característica própria desta criar conceitos, mas sim da Filosofia, segundo os filósofos franceses.

Com base nisto, tendo a Pedagogia do Conceito em foco, é possível entender que ela não é algo pronto, mas é possibilidade de criação, “como a Filosofia a ser feita” (BIANCO, 2002, p. 6). Sobre o sentido da Pedagogia de Conceitos, o filósofo Giuseppe Bianco aponta que "ela busca suscitar a criação e aprendizagem, partindo de casos de criação do conceito singular" (BIANCO, 2002, p. 16 - 17). Nesta perspectiva, buscamos uma Filosofia na qual o professor possa, em sua sala de aula, mediar e viabilizar ao estudante uma aproximação com os conceitos, provocando-os e incitando inquietações, e não, somente, uma reprodução dos saberes voltados à História da Filosofia e do pensamento filosófico. 
Buscamos promover um ensino que gere problematizações filosóficas e, assim, fomente a habilidade de um pensar autônomo, isto é, um pensamento que não se submeta ao pensamento de outrem, fornecendo as ferramentas necessárias para a construção dos seus saberes. Estes últimos, diferentes dos saberes promovidos por um ensino que se paute apenas na memorização dos conteúdos de Filosofia do Ensino Médio.

A partir dessas considerações, ponderamos que a proposta de aplicação da Pedagogia do Conceito ao Ensino de Filosofia no Ensino Médio vem dialogar com as propostas decorrentes dos documentos que regem o Ensino Médio, como as Orientações Curriculares para o Ensino Médio: Ciências Humanas e suas Tecnologias quando apontam para:

(...) o aprimoramento do educando como ser humano, sua formação ética, desenvolvimento de sua autonomia intelectual e de seu pensamento crítico, sua preparação para o mundo do trabalho e o desenvolvimento de competências para continuar seu aprendizado (BRASIL, 2006, p. 7).

Compreendemos que seja indispensável incitar o pensamento crítico do estudante do Ensino Médio, contribuindo dessa forma para seu futuro enquanto cidadão capaz de estabelecer leituras críticas do meio no qual esteja inserido. Com a finalidade de colaborar com o Ensino de Filosofia, percebemos que a Pedagogia do Conceito promove no ambiente escolar uma espécie de itinerário filosófico, de percurso do estudante ao conceito, sendo capaz de envolver e provocar o estudante de Filosofia no Ensino Médio.

Longe de qualquer alusão em transformar o estudante do Ensino Médio em filósofo, destacamos que a supramencionada forma de ensino visa desenvolver nos estudantes de Filosofia a capacidade de pensar o movimento de criação de conceitos, de criar ressignificações e apropriações filosóficas, visto que a própria atividade de criação e investigação de conceitos pode oportunizar ao estudante um espaço de fato investigativo e filosófico, no que concerne pensar o conhecimento destes de modo contínuo no ambiente escolar.

Nessa perspectiva, Junot (2013, p. 20) na obra Filosofia: Caminhos do Ensinar e Aprender sugere que "é necessário que o professor de Filosofia seja o filósofo, que ele experimente a Filosofia no pensamento. Só assim ele pode ser esse mediador". Para demonstrar mais claramente essa via de pensamento, visando estabelecer um diálogo da Pedagogia do Conceito com o Ensino de Filosofia, destacamos a compreensão de Bianco (2002, p. 2) em sua obra Gilles Deleuze Educador: sobre a Pedagogia do Conceito quando recorre à compreensão da Pedagogia do Conceito indicando que ela é: 
(...) apresentada por Deleuze e Guattari como a única postura filosófica que permite que o pensamento escape da doxa do discurso pseudofilosófico das disciplinas da comunicação contra as quais Deleuze tanto lutou em toda sua trajetória filosófica e, de modo particular, nos últimos anos de sua vida.

Em consequência de uma ação que escape da doxa (opinião, conhecimento não racional), sugerimos uma proposta de ensino diferenciado que venha a contribuir com a Filosofia, um ensino que não se detenha somente aos estudos historiográficos da Filosofia, pautado apenas na memorização. Em contrapartida, refletimos sobre a possibilidade de pensar e investigar o processo de criação conceitual, de pensar os motivos que levaram alguns filósofos desenvolverem seus posicionamentos filosóficos na História da Filosofia, seus conceitos, e os acontecimentos que os motivaram.

Pensando no Ensino de Filosofia, percebemos nas palavras do filósofo brasileiro Junot em sua obra Ensino de Filosofia: Questões Fundamentais que é necessário pensar estratégias de ensino na qual "cada aluno deve ser convidado a tornar-se estudante, e o estudante, um leitor da vida, de sua realidade, de suas vicissitudes. Assim, cada um será mobilizado pela própria dinâmica existencial e pelas provocações da realidade" (JUNOT, 2014, p. 16), portanto, o não vemos o ensino como sendo apenas um movimento de acumulação de saberes.

Sob o viés da Filosofia deleuzo-guattariana, podemos considerar que o filósofo, enquanto amigo do conceito, é aquele que pode pensar a criação conceitual, e referente ao conceito, em especifico a Pedagogia do Conceito, vemos uma oportunidade de pensar por meio dinâmica existencial, investigar o itinerário dos filósofos buscando convidar os estudantes do Ensino Médio a viverem essa experiência.

Entendemos ser de suma importância desenvolver um diálogo dos estudantes do Ensino Médio com a Pedagogia do Conceito e com acontecimentos que envolvem os discentes, em suas diversas realidades sociais. Assim sendo, o trabalho concentra-se em si, em investigar o desenvolvimento deste processo na sala de aula de Filosofia e busca suas possíveis contribuições para o Ensino de Filosofia. Sobre o pensamento voltado ao Acontecimento, os filósofos Deleuze e Guattari apontam que:

A grandeza de uma Filosofia avalia-se pela natureza dos acontecimentos aos quais seus conceitos nos convocam, ou que ela nos torna capazes de depurar em conceitos. Portanto, é necessário experimentar em seus mínimos detalhes o vínculo único, exclusivo, dos conceitos com a Filosofia como disciplina criadora. O conceito pertence a Filosofia e só a ela pertence. (DELEUZE; GUATTARI, 1992, p. 47) 
Avaliamos que um ensino pautado na Pedagogia do Conceito como uma forma diferenciada de abordar o ensino filosófico, de promover movimentos, acontecimentos, busca também entender a História da Filosofia como processo importante para a Filosofia, mas não como Filosofia.

A Filosofia é criação de conceitos, é ressignificação, e é ela que fomenta em nós a capacidade de pensar e criar conceitos. No entanto, "a exclusividade da criação de conceitos assegura à Filosofia uma função, mas não lhe dá nenhuma proeminência, nenhum privilégio, pois há outras maneiras de pensar e criar, outros modos de ideação que não têm que passar por conceitos, como o pensamento cientifico" (DELEUZE; GUATTARI, p. 16), isto é, a capacidade de pensar, de criar, bem como de refletir, comunicar e contemplar, necessariamente não são específicos da Filosofia, exceto quando parte de conceitos, os quais são propriamente filosóficos.

A Pedagogia do Conceito, bem como grande parte da Filosofia deleuzo-guattariana apresenta que a História da Filosofia possui sua devida importância, mas sendo ela o caminho, não a própria Filosofia, como asseguram Deleuze e Guattari (1992, p. 124 - 125) quando afirmam que "não se pode reduzir a Filosofia a sua própria história, porque a Filosofia não cessa de se arrancar dessa história para criar novos conceitos, que recaem na história, mas não provem dela”. As colocações dos filósofos franceses conduzem uma percepção crítica ao processo apenas historiográfico. O professor, quando preocupado em reduzir a Filosofia apenas à sua história, não pondera questões voltadas para a emancipação do estudante, que propicie sua autonomia intelectual ou incite problematizações e criações de conceitos, que são consideravelmente significativos no que se refere ao desenvolvimento do processo educacional com ênfase para a formação cidadã e no processo de investigação filosófica.

\section{O conceito enquanto especificidade da filosofia deleuzo-guattariana}

Na compreensão filosófica pautada na perspectiva deleuzo-guattariana, o conceito é o principal elemento que garante a especificidade da Filosofia. Assim sendo, nos cabe enfatizar tal posicionamento, visto que o conceito se distingue como característica marcante para Filosofia, bem como para o filósofo, nessa abordagem filosófica. Segundo Deleuze e Guattari (1994, p. 13):

É porque o conceito deve ser criado que ele remete ao filosofo como aquele que o tem em potência [...] as ciências, as artes, as Filosofias são igualmente 
criadoras, mesmo se compete apenas a Filosofia criar conceitos no sentido estrito. Os conceitos não nos esperam inteiramente feitos, como corpos celestes. Não há céu para os conceitos. Eles devem ser inventados, fabricados ou antes criados, e não seriam nada sem a assinatura daqueles que os criam.

Tendo como foco o ensino norteado pela Pedagogia do Conceito, buscamos dialogar com um Ensino de Filosofia que priorize o conceito enquanto elemento propriamente filosófico, visto que os filósofos franceses atribuem o conceito à Filosofia, de modo que a mesma seja, em sentido estrito, criadora de conceitos; enquanto para às artes cabem os afectos e perceptos, para à ciência, cabem os functivos. Desse modo, cabem aos professores de Filosofia estimular a construção de um pensar filosófico que viabilize a criação de conceitos, para que os estudantes possam adentrar no universo dos conceitos.

Dessa forma, compreendendo a Filosofia enquanto criação conceitual, os filósofos brasileiros Renata Aspis e Silvio Gallo em sua obra Ensinar Filosofia: um livro para professores descrevem a Filosofia como sendo:

(...) uma disciplina do pensamento que nos leva a criar conceitos, é pensamento que confere significado à cultura na medida em que pratica sua síntese conceitual, sendo assim, em cada época, a sua verdade. O pensamento filosófico, se considerado assim, não é apenas exercício de pensamento reflexivo e rigoroso, mas é, talvez principalmente, criação" (ASPIS; GALLO, 2009, p. 14).

Dentro dessa relação Filosofia e conceito, se torna mais evidenciado nosso posicionamento em atribuir como especificidade, dentro da abordagem filosófica deleuzoguattariana, o conceito para a Filosofia. Observamos também, segundo Silvio Gallo, em sua obra Metodologia do Ensino de Filosofia: uma didática para o ensino médio, que a Filosofia pode apresentar algumas especificidades em geral, mas o filósofo brasileiro atribui como característica primordial à Filosofia, o conceito. Desse modo, ele elenca algumas características antes de chegar a sua conclusão, de modo a apontar que:

Podemos tomar como três as principais características da Filosofia: 1) trata-se de um pensamento conceitual: enquanto saber, ela é sempre produto de pensamento, é uma experiência de pensamento. Mas o que caracteriza a Filosofia, como veremos a seguir, é que ele é uma experiência de pensamento que procede por conceitos, que cria conceitos, à diferença da ciência e da arte; 2) apresenta um caráter dialógico: ela não se caracteriza como um saber fechado, uma verdade dogmática, mas como um saber que se experimenta, que se confronta, consigo mesmo e com os outros, que se abre ao diálogo com outros saberes, um saber aberto e em construção coletiva; 3) possibilita a postura de crítica radical: a atitude filosófica é a da não conformação, do 
questionamento constante, da busca das raízes das coisas, não se contentando com respostas prontas e sempre colocando em xeque as posturas dogmáticas e as certezas apressadas (GALLO, 2012, p. 54).

A característica marcante da Filosofia é o conceito, visto que o caráter dialógico e a postura crítica também estão presentes em outros saberes, como por exemplo na geografia, que pode assumir uma postura crítica acerca de uma temática pertinente a sua área de atuação. No entanto, referente ao conceito, temos toda uma abordagem que reforça a este a especificidade da Filosofia, como vemos segundo os filósofos Deleuze e Guattari (1994, p. 28) quando mostram que "na Filosofia, não se cria conceitos, a não ser em função dos problemas que se consideram mal vistos ou mal colocados (Pedagogia do Conceito)".

Vale salientar e destacar que a compreensão de Filosofia para Deleuze e Guattari (1992, p. 14) reforça ao conceito sua especificidade, enquanto descartam algumas características geralmente atribuídas à Filosofia, como vemos abaixo:

\footnotetext{
Ela não é contemplação, pois as contemplações são as coisas elas mesmas enquanto vistas na criação de seus próprios conceitos. Ela não é reflexão, porque ninguém precisa de Filosofia para refletir sobre o que quer que seja: acredita-se dar muito a Filosofia fazendo dela a arte da reflexão, mas retira-se tudo dela, pois os matemáticos como tais não esperaram jamais os filósofos para refletir sobre a matemática, nem os artistas sobre a pintura ou a música; dizer que eles se tornam então filósofos é uma brincadeira de mau gosto, já que sua reflexão pertence a sua criação respectiva. E a Filosofia não encontra nenhum refúgio último na comunicação, que não trabalha em potência a não ser de opiniões, para criar o "consenso" e não o conceito.
}

Tona-se notável que a reflexão, contemplação e comunicação cabem a distintas áreas dos saberes, não sendo algo característico e intrínseco da Filosofia. Em suma, compreendemos que a investigação acerca da Pedagogia do Conceito para o Ensino de Filosofia no Ensino Médio pode, de modo contínuo, corroborar com o desenvolvimento das atitudes filosóficas no espaço da sala de aula Filosofia, bem como incitar a investigação acerca do movimento de criação de conceitos.

\section{Considerações finais}

Consideramos que nosso artigo acerca da Pedagogia do Conceito se justifica pelo interesse em analisar atentamente correlações estabelecidas do uso desta proposta conceitual filosófica nas salas de aulas de Filosofia no Ensino Médio, de modo que se possa explorar as 
conexões entre o ensino voltado para História da Filosofia e da Pedagogia do Conceito no espaço escolar, contendo como pressuposto base à contribuição ao Ensino de Filosofia para os estudantes do Ensino Médio.

Assim, nosso trabalho tem como aprofundamento estudar a Pedagogia do Conceito para nossas discussões e leituras em torno desta, intermediado pelas discussões em torno do Ensino de Filosofia no Ensino Médio no processo educacional, voltado ao ensino filosófico. Nesse sentido, buscamos um ensino que vise contribuir com a formação dos estudantes, no que se refere ao desenvolvimento da capacidade de um pensar filosófico, de desenvolver uma educação filosófica e da própria atitude filosófica, em vista das necessidades de contribuição ao processo formativo dos estudantes.

Diante da investigação de um Ensino de Filosofia diferenciado das aulas convencionais, pautada em volta da História da Filosofia, podemos concluir que as medidas que possibilitam o desenvolvimento de um estudo mais atento ao espaço escolar são provenientes da realidade dos estudantes de Filosofia no Ensino Médio e da viabilidade de criação de estratégias que venham a contribuir com as aulas de Filosofia.

Portanto, a Pedagogia do Conceito possibilita a oportunidade de pensar a Filosofia enquanto criadora de conceitos. Ao passo que tal investigação é pensando com foco no Ensino de Filosofia, entendemos que sua aplicabilidade fornece aos estudantes a capacidade de pensar a criação conceitual, de problematizar, de buscar compreender itinerário filosófico de alguns filósofos, e assim fomentar o filosofar no ambiente escolar, pautado numa proposta de ensino que vise a atitude filosófica, o questionamento, e, principalmente, os conceitos, contribuindo, assim, para a formação de um perfil filosófico em estudantes.

\section{Referências}

ASPIS, Renata Lima; GALLO, Sílvio. Ensinar Filosofia: um livro para professores. São Paulo: Atta Mídia e Educação, 2009.

BIANCO, Giuseppe. Gilles Deleuze Educador: sobre a Pedagogia do Conceito. Disponível em: 〈www.seer.ufrgs.br/educacaoerealidade/article/download/25927/15195> Acesso em: 09 set. 2016.

BRASIL, Ministério da Educação. Lei de Diretrizes e Bases Curriculares. Disponível em:〈http://www.planalto.gov.br/ccivil_03/leis/L9394.htm> Acesso em: 08 set. 2016.

Orientações Curriculares para o Ensino Médio: Ciências da Natureza, Matemática e suas Tecnologias. Brasília: Ministério da Educação, Secretaria de Educação Básica, v. 2, 2006.

Secretaria de Educação Média e Tecnológica. PCN + Ensino Médio: Orientações Educacionais Complementares aos Parâmetros Curriculares Nacionais. Ciências Humanas 
suas Tecnologias. Brasília: MEC, SEMTEC, 2002.

DELEUZE, Gilles; GUATTARI, Félix. O que é a Filosofia? Trad. Bento Prado Jr e Alberto Alonso Muñoz. 3. Ed. - Rio de Janeiro: Ed. 34, 1992.

GALLO, Sílvio. Deleuze e a Educação. Belo Horizonte: Autêntica, 2003.

Metodologia do Ensino de Filosofia: Uma Didática Para o Ensino Médio. Campinas: Papirus, 2012.

JUNOT, Cornélio Matos. Ensino de Filosofia: Questões Fundamentais. Recife: Ed. Universitária da UFPE, 2014.

2013.

Filosofia: Caminhos do Ensinar e Aprender. Recife: Ed. Universitária da UFPE, 